\title{
Database of bomb crater pools in Tommelen nature reserve, Belgium
}

Pieter Lemmens (iD, Tom De Bie, Els De Roeck, Dirk Ercken, Leo Vanhecke, Koen Martens \& Luc De Meester
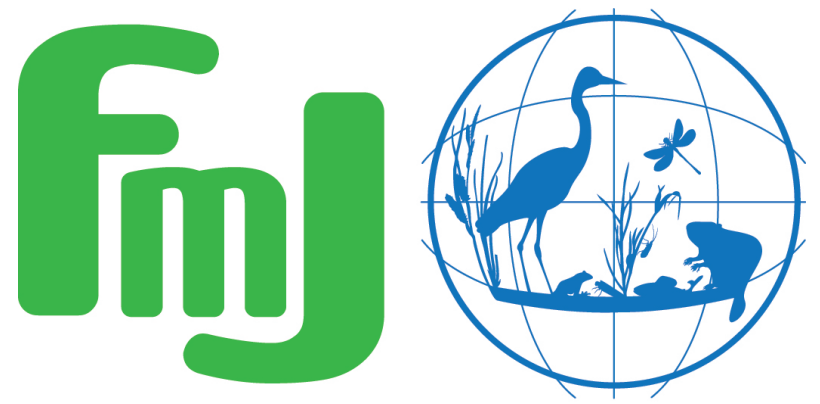

Freshwater Metadata Journal 



\title{
Database of bomb crater pools in Tommelen nature reserve, Belgium
}

\author{
Pieter Lemmens ${ }^{1}$ iD , Tom De Bie ${ }^{1}$, Els De Roeck ${ }^{2}$, Dirk Ercken ${ }^{1}$, Leo Vanhecke, Koen \\ Martens $^{2} \&$ Luc De Meester ${ }^{1}$ \\ 1 Laboratory of Aquatic Ecology, Evolution and Conservation, Leuven, Belgium; corresponding author: pieter.lemmens@kuleuven.be \\ 2 Royal Belgian Institute of Natural Sciences, Brussels, Belgium \\ 3 National Botanical Garden, Meise, Belgium
}

Please cite this paper as follows: Lemmens, P., De Bie, T., De Roeck, E., Ercken, D., Vanhecke, L., Martens, K. \& De Meester, L., 2018. Database of bomb crater pools in Tommelen nature reserve, Belgium. Freshwater Metadata Journal 40: 1-7. https://doi.org/10.15504/fmj.2018.40

Received: 2018-10-18 / Published: 2018-10-19

\section{Keywords}

bomb crater ponds, occurrences, environmental variables, Tommelen, Belgium

\section{Short description of the dataset/summary}

The Tommelen dataset contains data from bomb crater pools $(n=23)$ at Tommelen nature reserve (Hasselt, Belgium) (122 pools in an area of $12 \mathrm{ha}$ ). These ponds have been sampled annually from 2007 until 2012. A subset of the investigated ponds has been dredged in winter 2008.

This database comprises biodiversity data on aquatic macro-invertebrates and macrophytes, as well as information on major local environmental variables. Aquatic macro-invertebrates were sampled in 2008 and 2009. Macrophytes data are available for 2007, 2010 and 2012 .

\section{General information}

dataset entry ID:

name of the dataset:

full name of the dataset:

dataset short name:

type of dataset:

data type:

science keywords according to GCMD:

$$
\text { SF_10 }
$$

Tommelen bomb crater pools

Tommelen

species (taxonomic group) per site database including environmental information

point data/observation data topic:

Biosphere, Biological Classification, Land Surface, Terrestrial Hydrosphere 
contact email:

tom.debie@kuleuven.be

contact institute:

KU Leuven

criteria for using this part of the dataset:

The dataset is publicly available (data portal, data archive) and can be used without restrictions, but dataset creator/data contributors must be informed prior to publication. Data must be acknowledged and cited correctly.

data contributor/owner 2:

contact name:

Dirk Ercken

contact email:

contact institute:

KU Leuven

criteria for using this part of the dataset:

The dataset is publicly available (data portal, data archive) and can be used without restrictions, but dataset creator/data contributors must be informed prior to publication. Data must be acknowledged and cited correctly.

data contributor/owner 3:

contact name:

Els De Roeck

contact email:

contact institute:

KU Leuven

criteria for using this part of the dataset:

The dataset is publicly available (data portal, data archive) and can be used without restrictions, but dataset creator/data contributors must be informed prior to publication. Data must be acknowledged and cited correctly.

data contributor/owner 4:

contact name:

Leo Vanhecke

contact email:

fd443644@skynet.be

contact institute:

National Botanical Garden

criteria for using this part of the dataset:

The dataset is publicly available (data portal, data archive) and can be used without restrictions, but dataset creator/data contributors must be informed prior to publication. Data must be acknowledged and cited correctly.

\section{data contributor/owner 5:}

contact name:

Pieter Lemmens

contact email:

contact institute:

pieter.lemmens@kuleuven.be

criteria for using this part of the dataset:

The dataset is publicly available (data portal, data archive) and can be used without restrictions, but dataset creator/data contributors must be informed prior to publication. Data must be acknowledged and cited correctly.

citation of this dataset:

author(s):

De Bie, T., Ercken, D., De Roeck, E., Vanhecke, L., Martens, K. \& De Meester, L.

title and journal (name, number, pages):

year:

Database of bomb crater pools in Tommelen nature reserve (Hasselt, Belgium)

doi:

2018

citation of the metadata:

author(s):

https://doi.org/10.15468/ywcg4j

title and journal (name, number, pages):

Lemmens P., De Bie T., De Roeck E., Ercken D., Vanhecke L., Martens K. \& De Meester L.

Database of bomb crater pools in Tommelen nature reserve, Belgium.

Freshwater Metadata Journal 40: 1-6 
year: 2018

doi: $\quad$ https://doi.org/10.15504/fmj.2018.40

\section{General data specifications}

regional coverage of the dataset:

spatial extent of the dataset: regional

continents: Europe

spatial extent (bounding coordinates):

southernmost latitude $\left[{ }^{\circ}\right]$ : $\quad 50.93$

easternmost longitude $\left[{ }^{\circ}\right]$ : $\quad 5.31$

countries: $\quad$ Europe: Belgium

world climatic regions according to Köppen:

Group C: temperate/mesothermal climates

freshwater ecoregions of the world (FEOW) according to WWF:

Europe: Central \& Western Europe

European ecoregions according to Illies (WFD):

ecosystem type:

covered timeframe:

comments:
Western Plains (ER13)

lakes/ponds

$2007-2012$

The coordinates of the bounding box represent the coordinates of the center of the nature reserve.

\section{Site specifications}

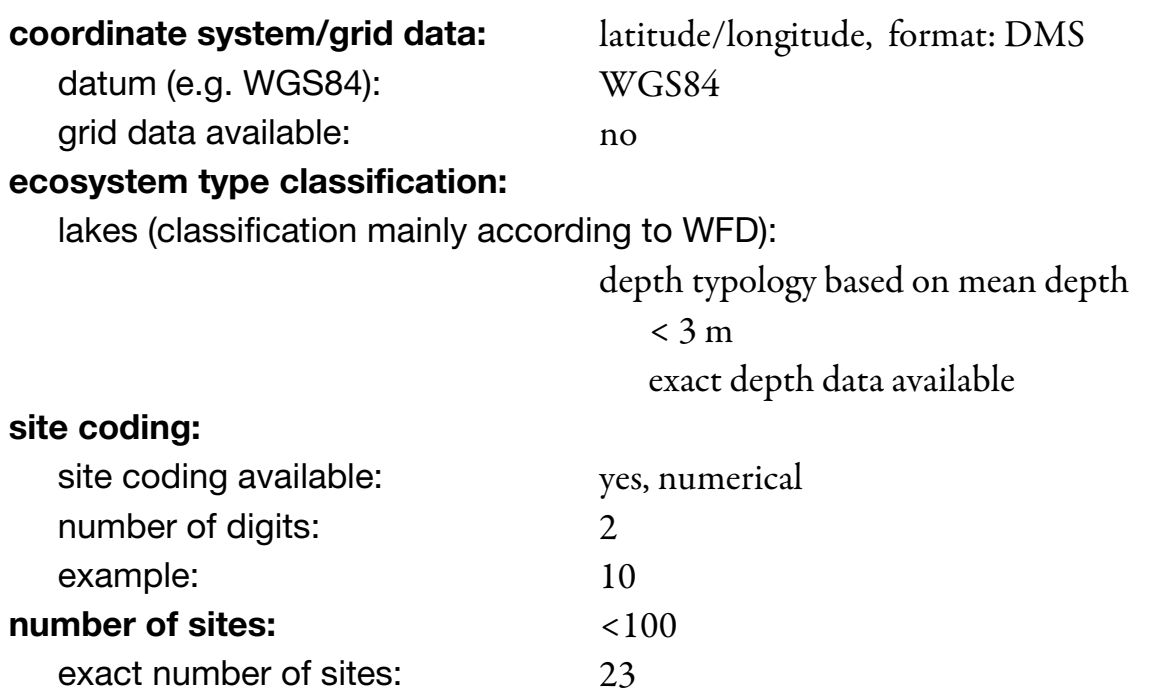

\section{Climate and environmental data}

climate related data:

environmental data:

available parameters per site: no climate data available

no environmental data per catchment available

mean depth

data source: field measurements

substrate composition 
physico-chemical data:

stressors influencing the sites: data source: field measurements

total $\mathrm{P}$, total $\mathrm{N}$, alkalinity, oxygen content, water temperature, $\mathrm{pH}$, conductivity, chlorophyll, suspended solids, substrate no stressor data available

\section{Biological data}

biological data origin:

from sampling,

organism group addressed:

macro-invertebrates (Mollusca, Crayfish, Ephemeroptera, Odonata, Coleoptera, Trichoptera, Chironomidae), macrophytes

\section{Sample specifications/sample resolution \\ macro-invertebrates: \\ sample information: \\ covered timeframe: \\ $2007-2012$ \\ historical data: \\ no \\ palaeo data: \\ no \\ season: \\ summer \\ temporal resolution/frequency of sampling: \\ time series data: \\ per year \\ no \\ taxonomic resolution: \\ level: \\ genus, species \\ percentage of species level data: 70 \\ taxonomic coding:}

taxalist according to:

reference(s):

see De Bie et al. (2012)

De Bie, T., De Meester, L., Brendonck, L., Martens, K., Goddeeris, B., Ercken, D., Hampel, H., Denys, L., Vanhecke, L., Van der Gucht, K., Van Wichelen, J., Vyverman, W., Declerck, S.A.J., 2012. Body size and dispersal mode as key traits determining metacommunity structure of aquatic organisms. Ecology Letters 15(7): 740-747.

\section{sample specifications:}

type:

semi-quantitative

replicate samples:

no

number of samples:

23

specification of method(s) used for sampling and sorting:

see De Bie et al. (2012)

reference(s):

De Bie, T., De Meester, L., Brendonck, L., Martens, K., Goddeeris, B., Ercken, D., Hampel, H., Denys, L., Vanhecke, L., Van der Gucht, K., Van Wichelen, J., Vyverman, W., Declerck, S.A.J., 2012. Body size and dispersal mode as key traits determining metacommunity structure of aquatic organisms. Ecology Letters 15(7): 740-747.

\section{macrophytes:}

sample information:

covered timeframe:

$2007-2012$

historical data:

no 


\begin{tabular}{ll} 
palaeo data: & \multicolumn{1}{c}{ no } \\
season: & $\begin{array}{l}\text { summer } \\
\text { temporal resolution/frequency of }\end{array}$ \\
& $\begin{array}{l}\text { per year } \\
\text { no }\end{array}$ \\
time series data: & \\
level: & species \\
percentage of species level data: & 100
\end{tabular}

taxonomic coding:

taxalist according to:

reference(s):

\section{sample specifications:}

type:

replicate samples:

number of samples:

see De Bie et al. (2012)

De Bie, T., De Meester, L., Brendonck, L., Martens, K., Goddeeris, B., Ercken, D., Hampel, H., Denys, L., Vanhecke, L., Van der Gucht, K., Van Wichelen, J., Vyverman, W., Declerck, S.A.J., 2012. Body size and dispersal mode as key traits determining metacommunity structure of aquatic organisms. Ecology Letters 15(7): 740-747.

semi-quantitative

no

23

specification of method(s) used for sampling and sorting: see De Bie et al. (2012)

reference(s): De Bie, T., De Meester, L., Brendonck, L., Martens, K., Goddeeris, B., Ercken, D., Hampel, H., Denys, L., Vanhecke, L., Van der Gucht, K., Van Wichelen, J., Vyverman, W., Declerck, S.A.J., 2012. Body size and dispersal mode as key traits determining metacommunity structure of aquatic organisms. Ecology Letters 15(7): 740-747.

\section{Other specifications}

\section{GIS layers, shape files related to the dataset:}

$\begin{array}{ll} & \text { no data available } \\ \text { availability of photos: } & \text { no } \\ \text { availability of maps: } & \text { no }\end{array}$

quality control procedures:

Were any quality control procedures applied to your dataset?

yes

quality control protocols and comments:

Species names were checked using the GBIF species list.

\section{Acknowledgements}

The authors acknowledge the Belgian Science Policy (Belspo) for funding the SAFRED project (Saving freshwater biodiversity research data - 2015-2018) that allowed processing and publishing the Tommelen data, amongst others. 


\section{References}

De Bie, T., De Meester, L., Brendonck, L., Martens, K., Goddeeris, B., Ercken, D., Hampel, H., Denys, L., Vanhecke, L., Van der Gucht, K., Van Wichelen, J., Vyverman, W. \& Declerck, S.A.J., 2012. Body size and dispersal mode as key traits determining metacommunity structure of aquatic organisms. Ecology Letters 15(7): 740-747.

https://doi.org/10.1111/j.1461-0248.2012.01794.x 